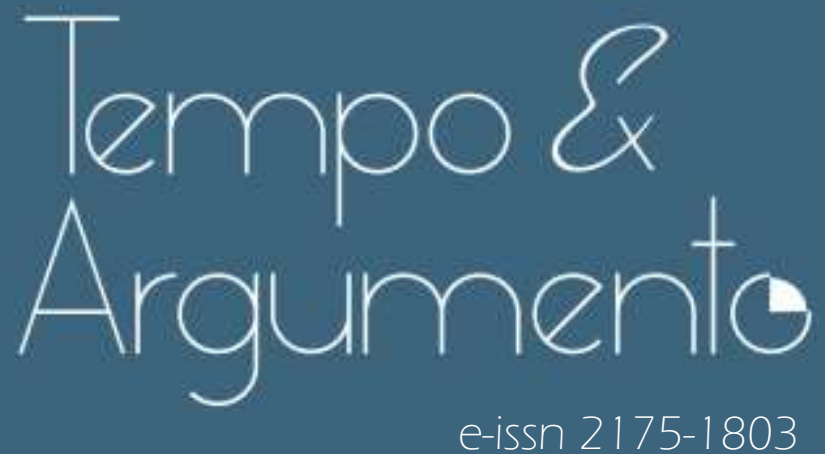

Representaciones sobre la enseñanza y el aprendizaje de la historia reciente peruana de los estudiantes del profesorado en ciencias sociales

- Augusta Valle Taiman

Doctora en Didáctica de la Historia, la Geografía y las Ciencias Sociales por la Universidad Autonoma de Barcelona.

Professor de la Pontificia Universidad Católica del Perú.

Lima - PERÚ

pucp.edu.pe/profesor/augusta-valle-taiman/

acvalle@pucp.edu.pe

(1) orcid.org/0000-0003-0491-2456

Para citar este articulo (ABNT):

VALLE TAIMAN, Augusta. Representaciones sobre la enseñanza y el aprendizaje de la historia reciente peruana de los estudiantes del profesorado en ciencias sociales.

Tempo e Argumento, Florianópolis, v. 13, n. 33, e0110, maio/ago. 2021.

doi

http://dx.doi.org/10.5965/2175180313332021 e0 110

Recebido: 26/02/2021

Aprovado: 28/05/2021 


\title{
Representaciones sobre la enseñanza y el aprendizaje de la historia reciente peruana de los estudiantes del profesorado en ciencias sociales
}

\begin{abstract}
Resumen
Esta investigación se centra en las representaciones de la enseñanza y del aprendizaje de la historia reciente peruana de los estudiantes del profesorado en ciencias sociales. Planteamos dos preguntas: cómo son estas representaciones de la enseñanza y del aprendizaje de la historia reciente; y si estas representaciones contribuirían al desarrollo de la competencia "construye interpretaciones históricas" establecida en el currículo nacional. En el marco de la teoría fundamentada, triangulamos la información recogida en un cuestionario, una narración y una entrevista semi-estructurada. Así, identificamos representaciones comunes y proponemos 4 grupos: narradores; identitarios; develadores; y analíticos. Las conclusiones muestran que los futuros maestros se sienten inseguros de abordar temas de historia reciente porque consideran que carecen de las estrategias y la formación disciplinar necesaria. Advertimos que predomina una representación de la enseñanza transmisiva y organizada en torno a los gobernantes como protagonistas. Sólo los "analíticos" la enfocan a partir de temas que vinculan con problemáticas del presente. Las representaciones del aprendizaje de los "narradores" evidencian que para ellos aprender historia es narrar objetivamente los hechos. Los "identitarios" y "develadores" consideran que aprender historia reciente significa reconocer la verdadera interpretación de la historia caracterizada por malos gobiernos, la corrupción, la injusticia y el enfrentamiento entre explotados y explotadores. Solo los "analíticos" proponen actividades relacionadas a habilidades para el desarrollo del pensamiento histórico que promoverían el logro de la competencia.
\end{abstract}

Palabras clave: formación inicial docente; historia reciente; representaciones de la enseñanza; representaciones del aprendizaje; historia del Perú.

\section{Representations of recent Peruvian history teaching and learning among prospective teachers in social sciences}

\begin{abstract}
This research focuses on the representations of recent Peruvian history teaching and learning among prospective teachers in social sciences. We ask two questions: how these representations of recent history teaching and learning are; and whether these representations might contribute to deal with the skill "build historical interpretations" provided for in the national curriculum. Within the grounded theory framework, we triangulate the information collected in a questionnaire, a narrative, and a semi-structured interview. Thus, we identified common representations and proposed 4 groups: narrators; identitarians; revealers; and analyticals. The conclusions show that prospective teachers feel insecure in addressing recent history topics because they see themselves as lacking the necessary strategies and disciplinary training. We notice the predominance of a representation of transmissive and organized teaching around rulers as protagonists. Only the 'analyticals' focus on teaching through topics that they link to current issues. The representations of learning among 'narrators' show that for them learning history is narrating facts objectively. The 'identitarians' and 'revealers' believe that learning recent history means recognizing the true interpretation of history characterized by bad government administration, corruption, injustice, and conflict between exploited and exploiters. Only the 'analyticals' propose activities related to skills to build historical thinking that might contribute to achieving the competence.
\end{abstract}

Keywords: Initial teacher training; recent history; representations of teaching; representations of learning; history of Peru. 


\section{Introducción}

Para los especialistas en didáctica de las ciencias sociales, un reto fundamental es que la enseñanza y el aprendizaje de la historia permitan comprender el presente y pensar en el futuro. Esta finalidad se ha recogido en el nuevo Currículo Nacional de la Educación Básica (CNEB-2016)1 del Perú, que empezó aplicarse en la secundaria desde el 2017. El área de ciencias sociales se compone de 3 competencias: una corresponde al aprendizaje de la historia; otra al de la geografía; y una última al de la economía. Así, se establece que desde la historia se debe desarrollar la competencia "construye interpretaciones históricas" (MINEDU, 2016, p. 62).

Si bien los cambios curriculares pueden implicar propuestas novedosas e interesantes, se reconoce que la renovación de la enseñanza depende en muchos sentidos de los docentes. Como indica Pagès (2000, p. 48): "el problema de la enseñanza de la historia no está, pues, en quienes aprenden, sino en quienes enseñan, en lo que enseñan y en cómo lo enseñan”. En ese sentido, no solo es importante quienes ya ejercen la docencia, sino también los futuros maestros. Nuevamente, Pagès (2000, p. 48) propone que "se considera necesario conocer el conocimiento del profesor, o del estudiante de profesor, sobre historia y el pensamiento histórico y, desde la formación inicial, enseñarles a intervenir en la práctica según estas nuevas ideas".

Por ello, se plantea aquí aproximarnos a las explicaciones que dan los futuros maestros de ciencias sociales de secundaria sobre la historia reciente desde la teoría de las representaciones. Esta investigación se pregunta cómo son las representaciones de la enseñanza y del aprendizaje de la historia reciente de los estudiantes del profesorado, y en segundo lugar si estas representaciones contribuirían al desarrollo de la competencia "construye interpretaciones históricas". Como un primer objetivo, proponemos elaborar una tipología de los estudiantes del profesorado en base a la identificación de sus representaciones de la enseñanza y del aprendizaje de la historia, y de los temas de historia

\footnotetext{
${ }^{1}$ Valga aclarar que cuando se hizo el trabajo de campo de la investigación, el CNEB-2016 estaba en pleno proceso de discusión. Las distintas versiones se iban compartiendo con grupos de maestros y especialistas para ser ajustadas. Sin embargo, estos futuros docentes trabajarán en las aulas con este nuevo currículo.
} 
Representaciones sobre la enseñanza y el aprendizaje de la historia reciente peruana de los estudiantes del profesorado en ciencias sociales

Augusta Valle Taiman

reciente. El segundo objetivo es discutir si estas representaciones contribuirían al desarrollo de la competencia del área de historia.

Consideramos que en los docentes y futuros maestros interactúan diversos tipos de representaciones, tanto sobre el pasado como sobre la enseñanza y el aprendizaje de la historia. Este conjunto de representaciones va a impactar en su práctica docente. Por lo tanto, sería necesario reconocerlas y considerarlas como un insumo para la reflexión en los programas de formación inicial y continua del profesorado, lo cual contribuiría a fortalecer la enseñanza de la historia reciente.

Este artículo recoge parte de la investigación desarrollada para la tesis doctoral realizada bajo la asesoría del Dr. Joan Pagés ${ }^{2}$. Pero incorpora nuevos elementos relacionados al CNEB-2016 y a las representaciones sobre el aprendizaje. Partimos de preguntas distintas que llevan a incluir nuevos aspectos de análisis.

\section{Marco conceptual}

En esta investigación, revisamos brevemente la teoría de las representaciones y su importancia en la formación inicial del profesorado. También examinamos las implicancias de la enseñanza de la historia reciente en la escuela. Finalmente, presentamos la competencia establecida en el CNEB2016 y planteamos su relación con el pensamiento histórico.

\section{Representaciones y la enseñanza de la historia}

Desde la psicología, ha sido muy importante el concepto de las representaciones sociales planteado por Moscovici, quien explica:

La representación social es una modalidad particular del conocimiento, cuya función es la elaboración de los

\footnotetext{
2 Para desarrollar este artículo se ha tomado la información recogida en los cuestionarios, las narraciones y las entrevistas realizadas en las ciudades de Ayacucho y Lima entre los años 2013 y 2015. Este material está consignado en la tesis doctoral: VALLE, Augusta. Los últimos 100 años de la Historia Peruana según los y las estudiantes del profesorado: estudio sobre sus representaciones de la historia y su conciencia histórica. 2017. Tesis (Doctorado en didáctica de la historia, la geografía y las ciencias sociales), Departamento de Didáctica de la Lenguna, la Literatura y las Ciencias Sociales, Universidad Autónoma de Barcelona, Bellaterra, 2017.495p.
} 
comportamientos y la comunicación entre los individuos. La representación es un corpus organizado de conocimientos y una de las actividades psíquicas gracias a las cuales los hombres hacen inteligible la realidad física y social, se integran en un grupo o en una relación cotidiana de intercambios, y liberan los poderes de su imaginación. (MOSCOVICI, 1979, p. 17-18)

Esta correspondencia entre el conocimiento, el comportamiento, la relación con los individuos y la comprensión del mundo social impacta en situaciones de enseñanza y aprendizaje como las que ocurren en la escuela.

Lo planteado por Moscovici (1979) ha sido referente importante para aproximarse a la formación inicial del profesorado. Pagès (2004, p. 173) señala la necesidad de que "los futuros profesionales tengan consciencia que poseen ideas sobre la profesión de maestro o profesor, que son ideas formadas a lo largo de su experiencia como alumnos...". Pagès (2004) resalta la importancia de la reflexión acerca de las representaciones sobre la enseñanza, los contenidos que enseñan y la profesión.

Adler (2008) y Avery (2010) consideran que, pese a que muchos programas de formación inicial del profesorado se definen como crítico-reflexivos, en la práctica no promueven suficientes espacios de reflexión. Así, terminan formando un docente más bien técnico que aplica un currículo; pero que no se detiene a pensar sobre lo que hace, las razones que guían su actuación en el aula, sus concepciones sobre el aprendizaje, las finalidades de la enseñanza o cómo sus propias experiencias escolares le influyen. En ese sentido, Adler (2008) coincide con Pagès (2004) en que los programas de formación inicial deberían promover la reflexión sobre las representaciones de los estudiantes.

En el ámbito iberoamericano, algunos estudios sobre la formación inicial del profesorado han identificado las representaciones sobre conceptos del área, los contenidos, la enseñanza de la historia, las finalidades y la profesión (GONZÁlEZ, 2013; ORTEGA; PAGĖS, 2017; PAGĖS; SANT, 2015; VALENCIA; VILLALÓN; PAGĖS, 2012). Estas investigaciones han demostrado la existencia de una diversidad de representaciones que no necesariamente coinciden con las propuestas curriculares. Además, han discutido su impacto en la conceptualización de la enseñanza y las prácticas. 
Consideramos que, igualmente, es necesario reconocer las representaciones del aprendizaje. Para comprenderlas, partimos de la propuesta sobre la influencia de las creencias epistemológicas del docente en los procesos de enseñanza y aprendizaje de Pozo, Scheuer, Mateos y Pérez Echeverría (2006). Los autores proponen que cuando se considera que el conocimiento es externo y proviene de una autoridad, deriva en una enseñanza transmisiva. Entonces, aprender implica repetir lo dicho por el docente. En cambio, cuando se supone que el sujeto es quien construye el conocimiento, se abre la posibilidad a diversas soluciones, lo cual promueve la argumentación y la discusión.

En la línea de comprender cómo se entienden la enseñanza y el aprendizaje de la historia, desde la didáctica de las ciencias sociales, un referente importante es la propuesta de Benejam (2004), quien analizó la relación entre 4 tradiciones epistemológicas de la ciencia -positivista, humanista, crítica y posmoderna- con la comprensión de la enseñanza de las ciencias sociales. Se plantea que en el paradigma positivista es el docente quien posee el conocimiento y sabe cómo transmitirlo a sus estudiantes. Bajo este paradigma, la enseñanza de la historia se enfoca en transmitir un conocimiento objetivo y unívoco, por lo cual se centra en el relato de hechos y se descarta la posibilidad de que el estudiante construya interpretaciones. En cambio, en los paradigmas humanista, crítico o posmoderno parece existir mayor posibilidad de que el estudiante construya alguna interpretación del pasado, aunque las dinámicas y los elementos que intervienen en este proceso de construcción varían según cada paradigma. Siguiendo a Benejam (2004), observamos que en el paradigma humanista el aprendizaje de las ciencias sociales y de la historia requiere la observación del entorno y de interacciones entre los estudiantes y el docente. De esta forma, los estudiantes construyen las interpretaciones de los procesos históricos. En cambio, en el paradigma crítico, la ideología y las relaciones de poder son centrales al interpretar el pasado y al aprender historia. Benejam señala que, bajo este paradigma, la didáctica se propone:

[...] descubrir la intencionalidad de los hechos y plantear posibles alternativas, lo que implica aceptar el conflicto y propiciar la argumentación entre diversas opciones [...] permite dar al alumno 
un papel activo, una visión de futuro y desarrollar una actitud de compromiso social y político. (BENEJAM, 2004, p. 41)

Así, el paradigma crítico podría reconocer que en la escuela coexisten y se debaten diversas interpretaciones producto de las diferencias ideológicas. Finalmente, en el paradigma posmoderno se considera fundamental que, al abordar el aprendizaje de los procesos históricos, los estudiantes y los maestros sean conscientes de que sus interpretaciones están condicionadas por "sus experiencias anteriores habidas en un determinado contexto cultural, social y afectivo e influidas por sus propias capacidades y estructuras mentales" (BENEJAM, 2004, p. 43). En este paradigma, se da importancia al contexto, se valoran las fuentes, se contrastan argumentos al tratar los procesos y se discuten y evalúan opciones de solución. Por ende, bajo este paradigma es fundamental reconocer la existencia de diversas interpretaciones y la necesidad de reflexionar y dialogar sobre éstas.

Si trasladamos la propuesta de Pozo et al. (2006) al aprendizaje de la historia, distinguimos 2 representaciones de éste. La primera entiende al maestro como la fuente del conocimiento histórico. En consecuencia, su función es transmitirlo y se considera que el estudiante aprendió cuando repite lo dicho por el docente. Esta representación del aprendizaje correspondería claramente al paradigma positivista analizado por Benejam (2004).

En cambio, si la representación del aprendizaje implica que el aprendiz construye el conocimiento histórico, se abre la posibilidad de que éste discuta, plantee ideas propias apoyadas en evidencias que considera válidas y logre construir una interpretación. Evidentemente, esta representación del aprendizaje implica que el maestro acepte una diversidad de interpretaciones históricas y el rol central en la clase pasa del docente al alumno. Esta segunda representación se puede asociar con lo propuesto por Benejam (2004) al paradigma posmoderno. Sin embargo, tanto el crítico como el humanista también deberían promover que el estudiante construya alguna interpretación propia. Es en esta segunda representación del aprendizaje, en la que el aprendiz construye su conocimiento, que se enmarca la propuesta del CNEB-2016, que establece que el estudiante debe desarrollar la competencia "construye interpretaciones históricas". 


\section{Las representaciones y la historia reciente}

En esta investigación, entendemos la historia reciente como el pasado cercano (FRANCO; LEVIN, 2007). Se trata de "una historia que todavía 'duele', abierta, no concluida" (STABILI, 2007, p. 16). Ello implica que aborda temas sobre los cuales subsisten memorias contrapuestas, que expresan las heridas abiertas y los conflictos no resueltos de una sociedad (EPSTEIN y PECK, 2018). La diversidad de memorias que pueden considerarse involucra una "organización de los conocimientos que posee un grupo respecto a un objeto social" (MOSCOVICl, 1979, p. 45). Ese objeto social serían las narraciones sobre la historia reciente.

Los currículos, al incluir temas de historia reciente, convierten a la escuela en un espacio donde la diversidad de memorias y perspectivas se "encuentran". Como indica González (2014), al enfrentar a la escuela a la controversia, se le da a la enseñanza de la historia un carácter perturbador e incómodo porque la aleja de su relato histórico neutral y cerrado, característico del paradigma positivista (BENEJAM, 2004). El peso cae entonces sobre los docentes, quienes señalan que carecen de capacitación y de estrategias pedagógicas para abordar estos hechos históricos que movilizan las emociones de estudiantes, familias, maestros y autoridades (AMÉZOLA, 2008; GONZÁLEZ, 2014; EPSTEIN; PECK, 2018).

Para el caso de los estudiantes del profesorado, Jara (2012, p. 19) resalta la importancia de las representaciones sobre la historia reciente al señalar que en “la formación inicial, estas representaciones deberían considerarse como puntos de partida para generar un pensamiento histórico y didáctico coherente y fundamentado".

Consideramos que los futuros docentes poseen sus propias representaciones del pasado reciente, las cuales se habrían construido a partir de sus experiencias como alumnos, de sus lecturas, de la relación con sus propios maestros y compañeros, de sus interacciones con su entorno, y de las experiencias familiares.

\section{La historia reciente peruana}

Para el caso peruano, se sabe que la investigación sobre la formación inicial del docente de las ciencias sociales es limitada (VALLE, 2018). 
Dentro de los temas más trabajados destaca la enseñanza del Conflicto Armado Interno (CAI) o la época de la violencia interna (1980-2000)3. Se han investigado los retos identificados por los docentes al abordar la historia reciente y se encuentran los mismos problemas reportados en las investigaciones internacionales ya mencionadas. A ello se suma el temor de los maestros de ser acusados de "apología al terrorismo", "negacionistas ante las violaciones a los derechos humanos", o simplemente que sus relatos sean cuestionados por considerarlos "incompletos", "falsos", O carentes de "objetividad" O comprometidos con una causa política (TRINIDAD, 2004; UCCELLI; AGÜERO; PEASE; PORTUGAL, 2017; VALLE, 2021).

Por otro lado, un estudio que no pretendió enfocarse en la historia reciente, pero que es muy importante para esta investigación, es el realizado por Portocarrero y Oliart (1989). Éste puso en evidencia el discurso histórico predominante en los maestros y los alumnos del último año de secundaria a fines de los años 1980. Entendían que el Perú era un país con abundantes riquezas naturales desaprovechadas por el desinterés de los gobernantes, quienes en lugar de cuidar los intereses nacionales estaban al servicio del imperialismo extranjero. Si bien el estudio no se realizó en el marco teórico de las representaciones, este discurso recoge una representación del pasado peruano marcada por el abuso de las élites, la injusticia, la victimización y la pérdida de grandes oportunidades de desarrollo económico. Los maestros en aquel momento creían que esta visión se oponía a la "historia oficial" escolar. Esta última pretendía transmitir un enfoque integrador, principalmente criollo y limeño, que negaba la realidad.

\section{El Nuevo Currículo y el pensamiento histórico}

De acuerdo con el CNEB-2016, el área de ciencias sociales se enmarca en la ciudadanía activa. La finalidad del área sería la comprensión del mundo en el

\footnotetext{
Este periodo está marcado por las acciones violentas de 2 grupos subversivos, Sendero Luminoso y el Movimiento Revolucionario Túpac Amaru (MRTA), y la respuesta del Estado, en la que se han dado numerosos casos de violaciones de los derechos humanos. Esta situación de violencia extrema dejó más de 60 mil muertos, principalmente población campesina quechua hablante de regiones como Ayacucho (COMISIÓN DE LA VERDAD Y RECONCILIACIÓN, 2004)
} 
que se vive. Así, el presente es producto del proceso histórico y la construcción del futuro es una responsabilidad de los ciudadanos, quienes pueden intervenir para transformar la sociedad (MINEDU, 2016). Para la enseñanza y el aprendizaje de la historia se establece la competencia "construye interpretaciones históricas", que se explica:

El estudiante sustenta una posición crítica sobre hechos y procesos históricos que ayuden a comprender el presente y sus desafíos, articulando el uso de distintas fuentes; la comprensión de los cambios temporales y la explicación de las múltiples causas y consecuencias de estos. Supone reconocerse como sujeto histórico, es decir, como protagonista de los procesos históricos y, como tal, producto de un pasado, pero que, a la vez, está construyendo su futuro. (MINEDU, 2016, p. 119)

Por lo tanto, es el estudiante quien asume una postura sobre los procesos históricos para entender el presente. Para lograr esta competencia se deben desarrollar 3 capacidades: interpreta críticamente fuentes diversas; comprende el tiempo histórico; y elabora explicaciones sobre procesos históricos (MINEDU, 2016). En esta propuesta curricular, cuando el estudiante emplea fuentes, implica que utiliza tanto fuentes primarias como secundarias. Es decir, la interpretación que se construye no debe ser una mera opinión, sino que se apoya en las investigaciones de los historiadores sobre el proceso histórico.

La propuesta del CNEB-2016 coincide con lo planteado por Pagès (2009) sobre el pensamiento histórico, que establece como su finalidad: formar ciudadanos capaces de comprender la realidad, su historicidad, y de asumir su protagonismo. Si analizamos estas capacidades tal como son descritas en el CNEB-2016 (MINEDU, 2016), observamos que implican diversas habilidades del pensamiento histórico: el interpretar críticamente diversas fuentes involucra la comprensión de la evidencia, la perspectiva y el uso de distintas fuentes tanto primarias como secundarias; el comprender el tiempo histórico alude a la conciencia histórico-temporal, que incluye el cambio y la continuidad; y la elaboración de explicaciones históricas se refiere a la comprensión de las múltiples causas y consecuencias, la relevancia y la interpretación histórica (PAGÈS, 2009; SANTISTEBAN; GONZÁLEZ; PAGÈS, 2010; SEIXAS; MORTON, 2013). Por lo tanto, el desarrollo de estas 3 capacidades debe permitir que se logre 
sustentar una posición con una perspectiva histórica apoyada en conocimientos históricos.

El pensamiento histórico implica una transformación en la enseñanza de la historia, porque se aleja de la enseñanza memorística y repetitiva para enfocarse en aproximar a los alumnos a cómo se construye el conocimiento histórico, permitiéndole abordar problemas del presente y del pasado, y comprender la existencia de visiones distintas de los hechos (LÉVESQUE, 2008; LÉVESQUE; CROTEAU, 2020). De esta manera, sería posible entender distintas perspectivas del pasado, lo que es fundamental para abordar la historia reciente.

Un aspecto central es preguntarse qué tan preparados están los docentes en formación para afrontar la enseñanza del pensamiento histórico. Armento (1991) coincide con Audigier (2001) en que la formación inicial del profesorado de ciencias sociales no ofrece espacios de reflexión sobre cómo se construye el conocimiento histórico. Es decir, no se aborda el uso y análisis de fuentes, ni el contraste de perspectivas, ni el análisis historiográfico, ni la conciencia históricotemporal. Por lo tanto, si el desarrollo del pensamiento histórico implica comprender la construcción del conocimiento (LÉVESQUE, 2008), y esta reflexión epistemológica no se promueve durante la formación, es probable que el pensamiento histórico y sus habilidades resulten ajenas al futuro docente.

Así, identificamos 2 problemas centrales en la formación inicial del profesorado: la comprensión de la naturaleza del conocimiento histórico; y el desarrollo de habilidades propias del pensamiento histórico. Para esta investigación, se han considerado como habilidades de este pensamiento: el análisis y uso de fuentes; la conciencia histórico-temporal; la contextualización de las perspectivas; y la multicausalidad. Estas habilidades del pensamiento histórico se han propuesto partiendo de los trabajos de Seixas y Morton (2013) y de Santisteban et al. (2010), y considerando las capacidades del CNEB-2016 y los desempeños propuestos en el Programa Curricular para la Educación Secundaria (2017). 


\section{Metodología}

Esta investigación se realizó en 2 universidades públicas peruanas, una en Ayacucho y otra en Lima. Ambas ofrecen la carrera de profesor de secundaria en la especialidad de ciencias sociales.

La investigación se realiza con un enfoque cualitativo, en el marco de la Teoría Fundamentada de Corbin y Strauss (2008). Optamos por esta propuesta porque permite la construcción de los conceptos a partir de la comparación constante de los datos recogidos. Además, se considera que este marco metodológico es muy útil cuando un problema de investigación no se ha trabajado con un determinado grupo (CRESWELL, 2009), lo cual ocurre con las representaciones de la historia reciente en los estudiantes del profesorado (VALLE, 2018).

Mora (2002) sugiere que para identificar y analizar las representaciones se requiere aproximarse al discurso que construye una persona desde varios ángulos. Por ello, recurrimos a la triangulación de la información recogida en 3 instrumentos. Primero, se aplicó un cuestionario con preguntas cerradas y abiertas, que nos dio una visión panorámica. Para profundizar en las ideas de los futuros maestros acerca de la enseñanza y el aprendizaje de la historia reciente, se les solicitó redactar una narración sobre procesos históricos de los últimos 100 años de la historia peruana. El análisis de las narraciones permitió afinar y reorganizar las primeras categorías y subcategorías. Finalmente, se utilizó una entrevista semi-estructurada para comprender mejor sus representaciones.

Para este artículo, hemos considerado solo los 25 participantes que desarrollaron los 3 instrumentos, 7 de Ayacucho y 18 de Lima. La mayoría de ellos cursaba el tercer año de formación.

A partir de la triangulación de la información, construimos una tipología de 4 grupos de estudiantes del profesorado. Cada grupo comparte una serie de rasgos en sus representaciones de:

a) Las finalidades de la enseñanza de la historia;

b) Cómo debe ser la enseñanza de la historia; 
c) La concepción que tiene sobre cómo se construye el conocimiento histórico y qué significa aprender historia;

d) Los contenidos de la historia reciente.

Para el desarrollo de la investigación, se contó con el consentimiento informado de cada uno y se estableció el compromiso de mantener el anonimato de los participantes. Por esta razón, todos los nombres han sido cambiados.

\section{Resultados y análisis}

¿Cómo entienden la historia reciente los estudiantes del profesorado?

Todos los futuros docentes de historia reconocen la importancia de la enseñanza de la historia reciente en la escuela. Las razones varían, pero principalmente se vinculan a la comprensión del presente. Para ellos, la historia reciente se puede definir a partir de 2 criterios: la cantidad de años transcurridos; o la vinculación con el presente.

Para un grupo la definición se marca por la distancia temporal. Así, un 23\% del total incluye todo lo ocurrido en los últimos 50 años, mientras que un 16\% solo lo acontecido en los últimos 20 años.

No obstante, la mayoría (61\%) prefiere definirla a partir de situaciones que implican "temas vivos en el presente" (Rodolfo, Entrevista, Lima, 2014, cit. en VALLE, 2017:213), lo cual coincide con lo propuesto por Stabili (2007) y Epstein y Peck (2018). Incluso, la Guerra del Pacífico (1879-1884) es considerada historia reciente por Luis. Él argumenta que sus efectos aún afectan al país, como la presencia de capitales chilenos en el Perú actual y "la explotación de los recursos nacionales" (Rodolfo, Entrevista, Lima, 2014, cit. en VALLE, 2017:213). Esta situación la entiende como una herida abierta desde la Guerra del Pacífico; por lo tanto, la califica como historia reciente.

En algunos casos, la comprensión de la historia reciente enfatiza el vínculo familiar, tal como indica Edson pensando en sus futuros estudiantes: "todo aquello que haya vivido su familia" (Entrevista, Lima, 2014, cit. en VALLE, 2017:214). María explica: "es lo que enlaza la historia de nuestros padres con la historia de nosotros" (Entrevista, Lima, 2014, cit. en VALLE, 2017:215). 
Otra razón por la que consideran importante la enseñanza de la historia es la cercanía temporal con el alumnado. Creen que los temas muy lejanos en el tiempo son indiferentes para los adolescentes. Un ejemplo lo expresa Inés: "si son temas actuales, ellos ya le van dando otro sentido, van entendiendo por qué las cosas están pasando" (Entrevista, Lima, 2014, cit. en VALLE, 2017:215).

Los futuros docentes reconocen que la enseñanza de la historia reciente no es fácil. Primero, porque en muchos casos no han tratado los temas durante su formación escolar, como ocurre con 24\% de los estudiantes de Lima y 33\% de los de Ayacucho. Además, cuando recuerdan que sí se les ha enseñado, reportan que principalmente han sido temas de historia universal, como la Guerra Fría. Consideran que los temas de historia del Perú fueron tratados de manera general -principalmente consistían en una lista de presidentes y hechos-.

A los estudiantes del profesorado les preocupa ser cuestionados por sus futuros alumnos, las familias, o las autoridades educativas. El hecho de que muchos protagonistas estén vivos y mantengan vigencia en la vida política del país constituye una tensión, tal como lo explica Alicia: "existe el chico [...] que sus padres están a favor del fujimorismo [...] entonces, van a estar en contra de lo que tú dices" (Entrevista, Lima, 2014, cit. en VALLE, 2017:218). También les inquieta sentir que carecen de una preparación sólida para afrontar situaciones en las que sus alumnos se desborden emocionalmente. Por ejemplo, Inés explica: "no sabes que de repente hay un alumno, [que] ha tenido un familiar, o [...] que sufre un atentado [...] Entonces, por ahí, tocar su susceptibilidad” (Entrevista, Lima, 2014, cit. en VALLE, 2017:218).

Además, no se sienten seguros de sus conocimientos históricos, pues suponen que no han sido formados en los temas claves para entender la historia reciente. Como indica Hugo: "yo siento que para abordar estos últimos temas de los últimos 50 años hay que saber más de economía [...] [esos temas] no sé cómo explicarlos" (Entrevista, Lima 2014, cit. en VALLE, 2017:218). Consideran que su formación disciplinar en historia económica carece de la solidez necesaria para la historia reciente.

Como se observa, los estudiantes del profesorado comparten las mismas inquietudes para abordar la historia reciente que los maestros en ejercicio 
(AMEZOLA, 2008; GONZÁLEZ, 2014; UCCELLI et al., 2017; EPSTEIN; PECK, 2018; VALLE, 2021).

Al definir los principales temas de la historia reciente se identifican 2 tendencias: unos que establecen una relación entre un gobierno y un problema; y otros que proponen una problemática. En el primer grupo encontramos ejemplos: Sendero Luminoso y Fujimori, el gobierno de Fujimori y la corrupción, la política neoliberal de Fujimori, la hiperinflación y la crisis económica de García; el Oncenio de Leguía y la entrega de recursos a capitales extranjeros; o el gobierno de velasco, la reforma agraria y la protección de los intereses nacionales. En el segundo grupo se propone: los problemas económicos del país; la situación del proletariado; la migración del campo a la ciudad; o la época del CAI. Los estudiantes del profesorado coinciden en que los temas más difíciles de abordar en la escuela serían el gobierno de Fujimori y la época del terrorismo.

\section{Tipología de los estudiantes del profesorado}

A continuación, presentamos 4 tipos de estudiantes del profesorado que hemos diferenciado a partir del análisis de sus representaciones de la enseñanza y del aprendizaje de la historia reciente.

Observamos que la mayoría de futuros maestros se encuentran en el grupo de los "reveladores"; no obstante, un grupo importante se puede ubicar en el de los "analíticos", tal como se muestra en el Gráfico 1.

Gráfico 1 - Distribución porcentual de los tipos de estudiantes del profesorado.

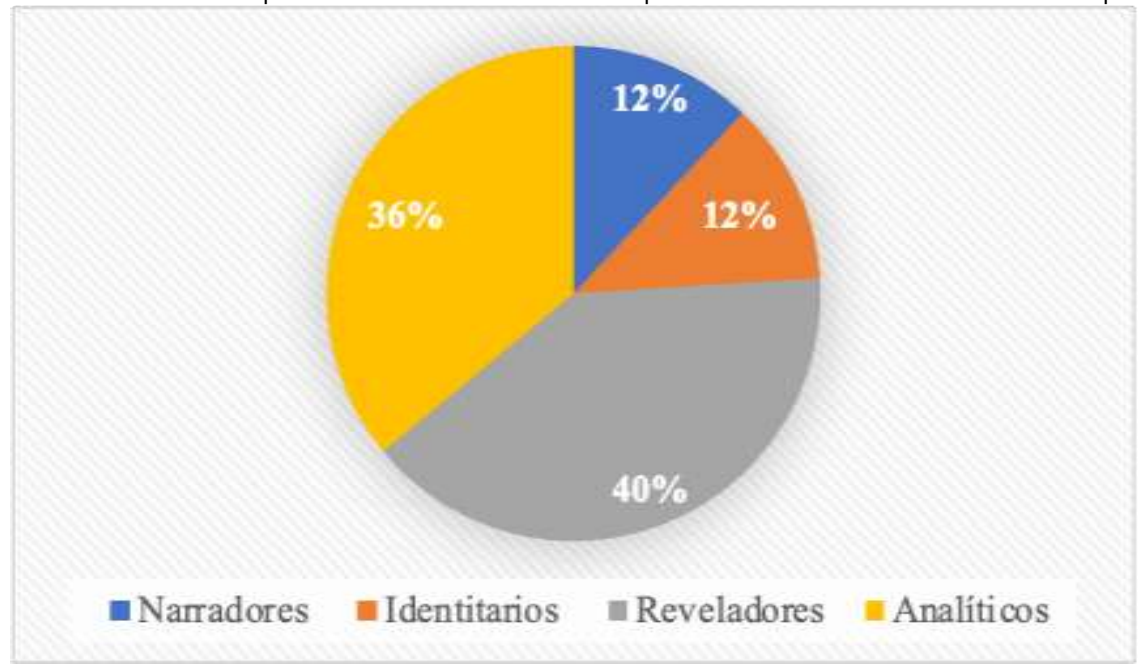

Fuente: Elaborada por el autor a partir de los datos recopilados en VALLE (2017), 2020 


\section{Narradores de la historia}

En esta categoría agrupamos a los futuros docentes que pretenden lograr una enseñanza absolutamente objetiva, a los que denominaremos "narradores". Para hacerlo, se enfocan en la narración de acontecimientos y en el orden cronológico. Tratan de transmitir principalmente información, pues consideran que el profesor de historia debe ser objetivo y narrar el pasado tal cual ocurrió, lo cual coincide con el paradigma positivista del análisis de Benejam (2004). Por ejemplo, Olga explica que su labor docente implica presentar: "la situación real de las cosas, desligado de todo interés económico y/o político" (Narración, Ayacucho, 2013, cit. en VALLE, 2017:347). Se entiende que el docente de historia debe carecer de una posición política, debe ser neutral. Esta misma objetividad de sus propias narraciones no ha permitido que se identifique una representación de los temas de la historia reciente, pues no se interpretan.

La enseñanza de la historia la estructuran en torno a gobiernos, "grandes personajes", obras y acontecimientos, sobre los que cuentan sin analizar ni interpretar. Ello hace que, si bien pueden identificar problemas de la historia reciente como la corrupción o la crisis económica, éstos no son analizados con una perspectiva temporal. Cada gobierno es presentado como un periodo independiente del otro, en orden sucesivo; sin identificar cambios y continuidades en el tiempo. Por ejemplo, María estructura su propuesta en torno a gobernantes y los asocia a problemas que no explica: "el gobierno de Fujimori y la gran corrupción. [...] el primer gobierno de Alan García y la repercusión económica - inflación” (Narración, Lima 2014, cit. en VALLE, 2017:348).

Estas representaciones coinciden en que la finalidad de la enseñanza de la historia es conocer el pasado para no repetir los errores en el futuro. Olga explica que: "así no se [tienen que] repetir". (Entrevista, Ayacucho 2013 cit. en VALLE, 2017: 201) La historia cumple el rol de "maestra vida" y solo en ese sentido aparece el futuro.

Este grupo tiene en común que los protagonistas de la historia son los gobernantes. De estos depende que se otorgue el voto a la mujer o la derrota a Sendero Luminoso. En este relato, la acción de otros sujetos históricos es invisibilizada; así, los grupos sociales carecen de agencia. 
La representación del profesor de historia como un narrador se vincula a su experiencia escolar. Tania recuerda: "mis dos últimos profesores de secundaria narraban la historia, lo contaban más como un cuento [...] Hacían que, por lo menos yo, me sentía atrapada en su narración" (Narración, Lima 2014, cit. en VALLE, 2017:348). Este modelo lo recupera para explicar cómo enseñaría la historia reciente: "les contaría sobre el 'decenio de Fujimori”" (Narración, Lima 2014. cit. en VALLE, 2017: 316). Observamos que la representación del maestro está vinculada a su propia experiencia como estudiante, tal como señalaban Pagès (2004), Adler (2008) y Avery (2010).

Concuerdan en considerar que una propuesta novedosa para la enseñanza es el uso de CDs y videos e imágenes. María indica: "presentamos la imagen de Fujimori, Montesinos, Vladivideos ${ }^{4}$. Nos ayudaran como motivación" (Narración, Lima 2014, cit. en VALLE, 2017:350). Este material se emplea como motivación, mas no como fuentes que se analizan. Por lo tanto, no estarían desarrollando la habilidad del uso de fuentes propia del pensamiento histórico.

Este grupo propone actividades de aprendizaje enfocadas en facilitar el recuerdo de la información y en ordenarla cronológicamente. Para esto último utilizan la línea de tiempo. Tania explica que ella pediría que elaboren: "una línea de tiempo con los diferentes atentados que se dieron durante la época del terrorismo" (Narración, Lima 2014, cit. en VALLE, 2017:350). Las líneas se usan para ordenar acontecimientos; pero no para entender la duración, la simultaneidad, el cambio y la continuidad. La representación del aprendizaje de la temporalidad es principalmente el orden cronológico, lo cual nuevamente se aleja del pensamiento histórico.

Este grupo también indica que la enseñanza debe promover la reflexión sobre la historia reciente. Tania explica que los temas de historia reciente propician: "el análisis, juicios críticos, reflexión de los alumnos" (Entrevista, Lima 2014, cit. en VALLE, 2017:354). Entonces, exploramos qué se estaba entendiendo por análisis, reflexión o juicio crítico para comprender la representación del

\footnotetext{
${ }^{4}$ Los Vladivideos constituyen el nombre con el que popularmente se denominan a los videos filmados por Vladimiro Montesinos durante el régimen de Fujimori que dejaron en evidencia el entramado de corrupción de dicho gobierno y la compra de los medios de comunicación y de congresistas.
} 
aprendizaje de la futura maestra. Ella aclara que el análisis implicaría que sus alumnos: "describan qué significa para cada uno esta época". Considera, también, que es muy difícil que "aprendan a criticar" un pasado más lejano porque "no lo han vivido" (Entrevista, Lima 2014, cit. en VALLE, 2017:354). En ese sentido, coincide con Inés, quien cree que los estudiantes solo pueden opinar sobre lo "cercano en el tiempo" (Entrevista, Lima 2014. cit. en VALLE, 2017: 353). Concluimos que, en esta representación, se trata de ofrecer al alumno la posibilidad de opinar sobre los temas recientes por la cercanía, pero no con una perspectiva en la que el conocimiento histórico sustente esa opinión.

Para este grupo de futuros docentes, la representación del aprendizaje de la historia se centra en recordar información transmitida por el docente. Por lo tanto, el conocimiento se construye externamente. Está en manos del maestro quien lo transmite al alumnado, lo cual coincide con uno de los casos propuesto por Pozo et al. (2006) y con la tradición positivista señalada por Benejam (2004).

Como en esta representación el papel del alumnado es pasivo, no se lograría promover el desarrollo de habilidades del pensamiento histórico como la multicausalidad, el análisis del cambio y la continuidad, la contextualización y el uso de diversas perspectivas para entender el pasado (MORTON; SEIXAS, 2013; SANTIESTEBAN et al., 2010). Si además consideramos que los protagonistas de la historia son los "grandes personajes", hay pocas posibilidades que el alumnado se reconozca como sujeto histórico. En consecuencia, están lejos de poder desarrollar la competencia que implica que sus estudiantes logren "construir interpretaciones históricas".

\section{Identitarios, las lecciones de los antepasados prehispánicos}

Bajo esta categoría de "identitarios" agrupamos a 3 estudiantes del profesorado que, en lugar de abordar temas de historia reciente, trataron intencionalmente la historia prehispánica. Pablo se enfocó en los Incas, Luis en los Wari ${ }^{5}$ y Elisa en Machu Picchu. Los 2 primeros temas son desarrollados por

\footnotetext{
5 La cultura Wari se desarrolló entre los siglos VII y XIII d.C. Su centro de desarrollo se ubicó en el actual territorio de Ayacucho y logró una notable expansión por buena parte del actual territorio del Perú.
} 
estudiantes de Ayacucho y el $3^{\circ}$ por una estudiante de Lima. Pese a que abordan hechos que no corresponden a la historia reciente, en sus narraciones y entrevistas se aprecia que los usan para cuestionarla. Por esa razón, analizamos sus representaciones y no los excluimos del grupo de estudio.

Para este grupo, la finalidad principal de la enseñanza de la historia es rescatar la identidad prehispánica; la cual sirve para cuestionar la historia reciente y el presente, y pensar el futuro. El pasado prehispánico representa un modelo ideal, una "edad dorada", que es la base de la identidad. Por ejemplo, Luis aclara que la cultura Wari es importante, puesto que es un referente de la riqueza cultural y el poder ayacuchano, porque "conquistaba pueblos vecinos" (Narración, Ayacucho, 2013, cit. en VALLE, 2017:358). Elisa explica que la finalidad de la enseñanza de la historia debería ser "ayudarnos a valorar el legado de nuestros antepasados” (Narración, Ayacucho, 2013, cit. en VALLE, 2017:360).

Cuando los futuros docentes de este grupo se refieren a su propia experiencia de aprendizaje en la escuela, cuestionan a sus maestros. Lo hacen por 2 motivos, el memorismo y por no promover las visitas a los sitios prehispánicos. Pablo señala que "los profesores [...] ni siquiera, eran capaces [...] de llevarme acá a Wari [...] muy cerca de mi pueblo. Para mí no me satisfacía ese tipo de educación" (Entrevista, Ayacucho, 2013, cit. en VALLE, 2017:361). En esta búsqueda de afianzar la identidad, resaltan la necesidad de visitar con el alumnado los sitios arqueológicos. Por ejemplo, Luis considera que es fundamental llevar a los estudiantes a conocer la Pampa de la Quinua, donde se desarrolló la batalla de Ayacucho, que puso fin a las luchas por la independencia del Perú. Pablo propone visitar los sitios arqueológicos Wari. La función que cumplen estas visitas es más reconocer espacios de conmemoración para afianzar la identidad. No se emplean oportunidades de trabajar con fuentes monumentales que se analizan y contrastan con otras. Por lo tanto, no guarda relación con las habilidades del pensamiento histórico.

Detrás de toda esta exaltación de la identidad, observamos una representación del docente como alguien que conoce la verdad sobre el presente, tal como indica Pablo: "tú ayudas a la sociedad a que no le venden los ojos [...] yo ayudaría a mis alumnos a que vean la realidad" (Entrevista, Ayacucho, 
2013, cit. en VALLE, 2017:362). Es el profesor de historia quien interpreta la realidad; no es el alumno quien analiza, contrasta y construye una interpretación. Para hacerlo, se vale del pasado porque este deja lecciones positivas que se han olvidado. Pablo propone:

[...] en esta época [época incaica] toda la gente era muy unida, trabajadora y no había ningún tipo de discriminación [...] en la época incaica había tres reglas fundamentales que era: el amasua, ama llulla y amaquella [...] en esa época era castigado aquel que robaba, mentía y aquel que era ocioso. [...] Es que los valores y la convivencia que había en la sociedad incaica se perdió en la sociedad actual porque como peruanos no sabemos aprovechar las buenas cosas que nos dejo [sic] nuestros antepasados. (PABLO, Narración, Ayacucho, 2013, cit. en VALLE, 2017:356-357)

El pasado prehispánico se idealiza y se contrasta con el presente. Consideramos que, para los estudiantes del profesorado de esta categoría, las conductas y los valores andinos serían siempre positivos y atemporales, mientras que lo occidental será negativo. De modo que, en esta representación, el sistema de valores y conductas humanas se traslada al presente y al futuro sin considerar los cambios ocurridos a través del tiempo. Así, la finalidad de la enseñanza de la historia es recuperarlos, lo cual se entiende como desarrollar la identidad.

Este grupo de futuros maestros se declara en contra del aprendizaje memorístico y repetitivo de la historia. Sin embargo, eso no significa que el alumnado construya sus propias interpretaciones. El maestro es la fuente del conocimiento, pero no solo de datos sino principalmente de interpretaciones. Pablo, a propósito de su referencia a que en el Tahuantinsuyo no existía discriminación, ociosidad, robo, mentiras y corrupción, expone:

[...] pero lo que vemos hoy día es que [...] la sociedad de hoy hay mentirosos, ociosos, rateros [...] esto es porque los propios gobernantes cometen estos errores. [...] Ningún gobierno tuvo esa visión de mejorar el Perú porque no les interesa. A ellos les interesó llenarse el bolsillo y prácticamente no ver cómo vive el Perú. (PABLO, Narración, Ayacucho, 2013, cit. en VALLE, 2017:357)

En la representación de Pablo, la historia reciente y el presente están marcados por la mentira, la ociosidad y el robo, lo cual sería la antítesis del pasado prehispánico. 
Así, para este grupo la representación de la historia reciente está marcada por una degradación de los valores prehispánicos que se habría iniciado con la conquista española y que habría continuado por culpa de los gobernantes. Los presidentes del siglo XX e inicios del siglo XXI se representan negativamente. Estos gobernantes son corruptos, se enriquecen ilícitamente y son indiferentes a las necesidades de la mayoría de la población.

Observamos que el conocimiento de la historia proviene del docente quien enseña a valorar el pasado prehispánico para que los estudiantes rescaten los valores y la identidad, y lo contrapongan con la realidad. Todo ello, con la esperanza de que finalmente se recuperen en el futuro. No se observa un desarrollo de las distintas habilidades del pensamiento histórico. Además, en esta perspectiva, el estudiante tendría pocas oportunidades de "construir interpretaciones históricas”, más bien debería concordar con la interpretación del docente.

\section{Reveladores de la verdadera historia}

Este grupo de estudiantes del profesorado, a quienes llamaremos "reveladores", cree que la historia oficial esconde la "verdad" sobre el proceso histórico peruano. En palabras de Alicia: "muchos jóvenes desconocen la realidad histórica del Perú y muchos de ellos tienen una idea tergiversada" (Narración, Lima, 2014, cit. en VALLE, 2017:373). Por lo tanto, la finalidad principal de la enseñanza es dar a conocer esta "verdadera historia", que constituye según Pedro “la realidad objetiva” (Narración, Lima, 2014. cit. en VALLE, 2017:373).

Esta representación de enseñar la "verdadera historia”, en el caso de muchos de los estudiantes del profesorado se vincula a sus propias experiencias de aprendizaje. Contrastan dos tipos de maestros. Por un lado, está su experiencia escolar en la que el maestro promovía la memorización y daba pocas oportunidades de participación y debate a los estudiantes. Tal es el caso de Laura, que comenta: "mi clase de historia en el colegio era completamente memorista [...] Muy pocas veces [...] tomaba opiniones [...] No hacíamos debates. Terminaba la exposición [con] ¿¿No hay preguntas’?” (Entrevista, Lima, 2014. cit. en VALLE, 2017:178). Por otro lado, aparece el docente de la academia 
preuniversitaria, institución en la que se prepararon para rendir el examen de admisión de sus respectivas universidades. Este docente representa un enfoque distinto, como explica Rodolfo: "allí se comienza a analizar la historia con un enfoque crítico" (Entrevista, Lima, 2014. cit. en VALLE, 2017:184). En palabras de Luz: "decidí ser profesora [...] porque necesitaba un cambio [...] enseñar la verdadera historia que aprendí en la academia" (Entrevista, Lima, 2014. cit. en VALLE, 2017:188). Nuevamente, observamos la influencia de sus propias experiencias como alumnos en su representación de ser docente de historia, tal como proponen Pagès (2004), Adler (2008) y Avery (2010).

Además de revelar la "verdadera historia", encontramos una segunda finalidad, expresada, expresada por Rodolfo: "la razón principal para enseñar la historia actual es [...] porque hay muchas cosas que se van repitiendo [...] para que [...] no se cometan los errores" (Entrevista, Lima, 2014. cit. en VALLE, 2017:375376). Estas situaciones repetitivas implican actos de corrupción, problemas económicos y escándalos políticos. La enseñanza de la historia tendría la finalidad de aprender de los errores del pasado. Precisamente, serían esos errores los que la historia oficial pretendería ocultar. Se trata de rasgos considerados comunes en toda la historia reciente, pero que pese a mantenerse en el tiempo, no se problematizan o analizan para identificar cambios y continuidades, y contextualizarlos. Estos rasgos se presentan fraccionados, pues se articulan en función de los gobiernos.

La temporalidad se entiende como una sucesión cronológica de gobernantes con características que se mantienen inalterables en el tiempo, hasta que aparecen interrupciones, pero se retorna a las prácticas anteriores. Ese es el caso del gobierno de Velasco. Laura explica:

[...] en los años 60 la estabilidad política, económica y social iba a sufrir un gran cambio debido al gran golpe de Estado [...] del General Juan Velasco Alvarado, quien aplicará grandes reformas como la Agraria [...] Esta política de gobierno será aplicada por sus sucesores hasta el año 79 donde [sic] el [...] Belaúnde tendrá la victoria en las elecciones. (LAURA, Narración, Lima, 2014. cit. en VALLE, 2017: 316) 
Las problemáticas no se contextualizan, solo se describen.

Al proponer sus estrategias de enseñanza, nuevamente las fuentes visuales y audiovisuales se incluyen como estrategias motivadoras. Laura explica que iniciaría el tema del gobierno de Fujimori con:

[...] Los 'vladivideos' [...] o la cara de Montesinos o Fujimori [...]. Les diría, 'Chicos ¿ustedes conocen a tal persona?'. [...]. Otro tipo de motivación sería unas historietas [...] considero que lo visual llama más la atención [...] [se trata de] curiosidades de repente llama más la atención del alumno. Luego desarrollo mi clase. (LAURA, Entrevista, Lima, 2014. cit. en VALLE, 2017: 376).

Es más, ni siquiera las fuentes visuales se consideran parte de la "clase", es decir, de lo que se debe aprender.

Para enseñar, creen importante usar algunos textos que contengan información sobre el gobierno. Pero este material no se analiza ni contrasta como establece el CNEB-2016 o se plantea en las habilidades del pensamiento histórico (MORTON; SEIXAS, 2013; SANTIESTEBAN et al., 2010).

Nuevamente, encontramos la mención a promover el desarrollo del sentido crítico del alumnado. Rodolfo explica que con ese objetivo se deben "diseñar [actividades para que] nuestros estudiantes de una forma crítica de ver la realidad de estos gobiernos dictadores [Leguía y Fujimori] que se enferman por el poder" (Narración, Lima, 2014. cit. en VALLE, 2017:179). Entonces, consideran necesario proponer oportunidades de participación y debate.

Es importante profundizar en el sentido que tiene para ellos el desarrollo del "juicio crítico". Como ejemplo se puede tomar la explicación que realiza Luz de cómo trabajaría el tema del gobierno de Fujimori:

[...] primero se debe pegar la imagen porque hay chicos que a veces no recuerdan bien [...] se puede preguntar ¿Ustedes saben quién es él? [...] ¿quién crees que ha sido?, "Un presidente profesora porque tiene la banda" [responderían]. (LUZ, Entrevista, Lima, 2013 en VALLE, 2017: 378)

A continuación, sería la docente quien explicaría los hechos ocurridos durante ese gobierno: 
[...] los datos precisos de lo que fue su gobierno. [Luego] preguntarles a los alumnos: “¿Qué hubieras hecho tú?” Pero se puede hacer un debate porque el tema de Fujimori se presta para un debate, opinión, ideas [...] Yo haría así mi clase. “¿Qué te pareció el gobierno de Fujimori?" [...] "¿qué opinan de la persona del expresidente Fujimori?” (LUZ, Entrevista, Lima, 2013 en VALLE, 2017: 378)

La propuesta de Luz es importante porque ejemplifica el interés compartido por este grupo en desarrollar una enseñanza que promueva la participación del alumnado. No obstante, al pedir la opinión sobre el gobierno, no queda muy claro cómo se construyen las opiniones: si éstas parten de un análisis del impacto de las medidas tomadas por el gobierno; o se trata más bien de una opinión que no se sostiene en la construcción del conocimiento histórico, es decir, en el análisis de fuentes y la discusión de evidencias.

Promover que se "construya una interpretación histórica", como indica la competencia del CNEB-2016, parece difícil porque este grupo comparte la representación de que enseñar historia implica la existencia de una interpretación única y verdadera que el maestro debe transmitir al estudiante. Por lo tanto, aprender historia implica repetir dicha interpretación. Así, el conocimiento histórico está en el maestro y el alumno aprende cuando lo reproduce.

Para ellos, aprender críticamente la historia reciente se entiende como compartir una representación de ese periodo caracterizada por: corrupción, mal gobierno, entreguismo al capital extranjero y dictadura. La responsabilidad de esta situación sería de los gobernantes. Edson evidencia esta representación al calificar al gobierno de: "enmarcado en una serie de hechos de corrupción [...] entreguistas, de espaldas a la situación social de las grandes mayorías" (Narración, Lima, 2014. cit. en VALLE, 2017:379). Rodolfo explica: “un retroceso político, social y económico de la población del Perú, a cambio de vender nuestro estado al mejor postor capitalista - norteamericano, la corrupción en el Perú ha sido un tema constante”. (Cuestionario, Lima, 2014. cit. en VALLE, 2017:310).

En esta representación hay una oposición constante entre el gobierno y "el pueblo". Este segundo término se refiere a sectores tan diversos como campesinos, indígenas y obreros sin precisar distinciones o cambios en los 
grupos sociales a través del tiempo. Junto a los gobernantes se ubican las élites, principalmente criollas y limeñas, que explotan al "pueblo". Así, expresa Felipe: "los hacendados explotadores enriquecen sus necesidades mientras el pueblo marginado tildados de cholos e indios no tienen acceso a ser terratenientes sino ser trabajadores eternos para el señor feudal". (Narración, Ayacucho, 2013. cit. en VALLE, 2017:372).

La representación expresa una oposición entre explotados y explotadores marcada por la injusticia y la desigualdad. Incluso, esta representación aparece también en algunos casos para explicar las acciones de Sendero Luminoso. Por ejemplo, Pedro señala que: "ellos quieren la justicia, igualdad para todos, pero los gobiernos no aceptan, porque ellos solo quieren riqueza, poder y eso no debería ser asi" (Narración, Ayacucho, 2013. cit en VALLE, 2017:3021-302).

Para este grupo, la excepción es el gobierno de Velasco. Este tiene una valoración positiva relacionada a la defensa de los intereses nacionales y de los sectores explotados. Por ejemplo, Edson señala que Velasco simboliza "la nacionalización de empresas" (Narración, Lima, 2013.cit. en VALLE, 2017: 368) y Liz considera que "la reforma agraria [...] fue de alguna manera un beneficio para el sector del campesinado" (Narración, Lima, 2013.cit. en VALLE, 2017: 365). En esta representación, pese a que Velasco quiebra el orden constitucional, no es categorizado como un dictador.

La representación del pasado identificada en este grupo coincide con la que encontraron a fines de los años 1980 Portocarrero y Oliart (1989). A ésta se agrega el tema de la corrupción. Probablemente, fue una representación que aprendieron en la academia preuniversitaria y se ha modificado muy poco con los cursos de historia que han llevado durante la carrera.

El proceso histórico reciente se centra en los gobernantes. De ellos depende el devenir histórico, no de otros grupos o fuerzas sociales. De modo tal que la reforma agraria se da gracias a Velasco, no a las acciones del campesinado ni se vincula con el contexto internacional de los años 1960 y 70 en América Latina. Este grupo de estudiantes del profesorado comparte una representación con un discurso nacionalista. Esta sería la representación de la historia crítica, 
que es considerada la única interpretación verdadera, calificando cualquier otra como un engaño.

Observamos que en esta representación hay elementos del paradigma crítico planteado por Benejam (2004), tales como tratar temas relevantes, considerar la intencionalidad y promover una opción de transformar la realidad, pero se impone la interpretación del presente y del pasado del docente. Por lo tanto, es poco factible que los estudiantes de la escuela tengan oportunidades para contrastar diversas perspectivas, más bien deberían descalificar aquellas "engañosas"; tampoco parece que se suscite el análisis de los cambios y de las continuidades. Dado que solo hay una interpretación válida, es poco probable que puedan promover que sus alumnos construyan sus propias interpretaciones históricas como establece el CNEB-2016.

\section{Analíticos, el pasado para explicar el presente}

Este grupo de futuros docentes que denominamos "analíticos" explica la historia reciente a partir de plantear un tema que representa un problema que vinculan con el presente. Este se analiza en un marco que generalmente no se limita a un gobierno. El análisis considera diversas causas y consecuencias, remarca cambios y continuidades.

Un rasgo importante es resaltar la relevancia del problema en el presente. Como ejemplos, encontramos: la migración del campo a la ciudad (Isaías) o Sendero Luminoso y su impacto en el presente sobre los movimientos de izquierda en el Perú (Vicente). La finalidad de la enseñanza de la historia es comprender los problemas del presente como producto de un proceso histórico; por ello se reconocen cambios y diversos contextos. Por ejemplo, Lorenzo, al tratar los problemas de la ruralidad que contribuyeron a asentar la violencia en las zonas de Ayacucho durante el CAl, dice: "todavía sigue vigente [...] por qué aún los pueblos afectados [...] siguen sufriendo, pero de otra manera. Es el caso de Chungui ${ }^{6}$ que tiene carencias económicas. Es un pueblo olvidado que no cuenta

\footnotetext{
${ }^{6}$ Chungui es un distrito de la provincia de La Mar, Ayacucho, en el que fallecieron más de 100 personas durante el CAI. Los testimonios recogidos por la Comisión de la Verdad y Reconciliación (CVR) respecto a los sucesos ocurridos señalan que el lugar fue víctima de numerosos ataques
} 
con los recursos básicos" (Narración, Lima, 2013.cit. en VALLE, 2017: 381). Para Lorenzo queda claro que, pese al tiempo transcurrido, existe una serie de características en las zonas más afectadas por el CAl en los Andes que se mantienen y problemas que no se han solucionado.

Este grupo no limita su concepción del tiempo histórico al orden cronológico. Resaltan la necesidad de analizar los cambios y las continuidades que se dan en el proceso histórico y vincularlo con el presente.

La enseñanza también se piensa vinculada al alumnado. Lorenzo propone que cada tema "tenga una correlación tanto con la comunidad como su país". (Entrevista, Lima, 2013.cit. en VALLE, 2017: 389). Se trata de enfocar los problemas nacionales en el contexto de los estudiantes.

En algunos casos, observamos que se explicita la relación entre la enseñanza de la historia y la ciudadanía participativa. Por ejemplo, Hugo propone que la historia permite: "involucrarse en temas de actualidad [...] decidir, tomar una postura" (Entrevista, Lima, 2013.cit. en VALLE, 2017: 390). Incluso, en este grupo la participación no se asocia solo al sufragio, sino también con la expresión de un reclamo a través de "protestas", como indica Abel (Narración, Lima, 2013.cit. en VALLE, 2017: 392). Vicente explica:

Yo creo que la historia se tiene que enseñar para ver los cambios y para poder en cierta manera acortar la tanta desigualdad que hay en el Perú [...]. Yo creo que tiene que ser una historia más analítica y buscar un cambio mejor para la sociedad en beneficio. (Entrevista, Lima, 2013.cit. en VALLE, 2017: 388)

Vicente recoge también otro rasgo común al grupo: promover que el alumnado reflexione en los cambios necesarios para construir una mejor sociedad; por lo tanto, tiene una proyección hacia el futuro.

Arturo, al referirse a la derrota de Sendero Luminoso, explica que: "no tuvo el apoyo total del pueblo, ya que este movimiento predicaba su ideología a través

\footnotetext{
de Sendero Luminoso en los que asesinaron a diversas autoridades. El más importante ocurrió en 1983, cuando Sendero Luminoso toma por asalto el pueblo. En 1984 se inician las incursiones del Ejército Peruano. Los campesinos y sus autoridades también fueron víctimas de la represión en manos del Estado, que los acusó de senderistas. Los testimonios recogidos por la CVR muestran la crueldad con la que militares, como el "Capitán Samuray", torturaron y asesinaron a los comuneros. Al respecto se puede revisar CVR (2004).
} 
de la violencia. Y esto, al contrario, alejó a los simpatizantes" (Narración, Lima, 2013.cit. en VALLE, 2017: 387). Por lo tanto, no es Fujimori quien derrota a Sendero Luminoso, sino es el "pueblo". La narración completa aborda con detalle cómo se expande la violencia y lo vincula con las razones por las que no logró atraer simpatizantes en muchas zonas andinas.

Advertimos que este grupo no enfoca la agencia del proceso histórico solo en los gobernantes. Más bien, reconocen que los ciudadanos pueden generar cambios. Por lo tanto, sus estudiantes son sujetos históricos con capacidad de intervenir en la construcción del futuro. Esta perspectiva es acorde a lo propuesto en el CNEB-2016 -tanto para la competencia de historia que reconoce al estudiante como sujeto histórico como para la ciudadanía-.

El análisis implica la discusión de las causas y consecuencias de los hechos y procesos.

Tomemos 2 ejemplos. Inés señala:

La Reforma Agraria impulsada por Velasco tuvo un fin de desarrollo nacional, pero las medidas para lograr dicho desarrollo no aseguraron el logro. La nacionalización de las empresas sin debida planificación trajo como consecuencia una fuga de inversión extranjera, el mal manejo administrativo terminó haciendo de dicha medida lo peor.

Se trató de valorar al campesino de la sierra dándoles tierra para que la produzcan, pero la tecnología para la producción agrícola no benefició. (Narración, Lima, 2013.cit. en VALLE, 2017: 384)

E Isaías propone:

El proceso de migración campo-ciudad [...] cambió en muchos aspectos la dinámica e interrelaciones sociales, a tal punto que ocasionó diversas costumbres, modificando la tradición cultural costeña. [...] El crecimiento demográfico y las necesidades que este implicaba, nunca pudieron ser cubiertas por el Estado. Se pensó diversas alternativas para menguar este déficit pero que en la práctica no pudieron ser reproducidas con éxito.

[...] en términos económicos [la migración] dinamizó la mano de obra en la capital y norte sobreexceden la demanda. (Narración, Lima, 2013.cit. en VALLE, 2017: 382) 
Observamos que, tanto en el caso de la reforma agraria como en el de la migración, se reconocen múltiples consecuencias -tanto positivas como negativas-.

Si bien ambos ejemplos evidencian que este grupo analiza causas y consecuencias, no nos queda claro si además de este análisis se promoverá que el alumnado las identifique en las fuentes.

Observamos que, al igual que en las otras categorías, este grupo también utiliza el video y las fuentes gráficas para motivar. No obstante, en las actividades promueven el trabajo con fuentes diversas. Lorenzo explica que para tratar el tema de Sendero Luminoso:

[...] podría usar [...] los videos de esa época [...] fuentes escritas [...] fuentes de imágenes, las cuales ayudarían mucho [para identificar] las distintas posturas. [...] buscar testimonios por ambos lados. Por ejemplo, puedo poner ejemplos del testimonio de un funcionario [...] de [...] Sendero [...] de la población. (Narración, Lima, 2013.cit. en VALLE, 2017: 391)

La propuesta de emplear diversas fuentes incluye testimonios que reflejan posturas distintas y contrastarlas. Incluso, se considera que los estudiantes construyan sus propias fuentes a partir de recopilar testimonios familiares y emplearlos como fuentes, tal como establece en la actualidad uno de los desempeños del MINEDU (2017). Abel explica:

[...] que entreviste a sus padres o abuelos [Conozca] dónde se encontraban en cuanto ocurrió ese hecho [refiriéndose a los atentados o matanzas]. Por último, pediría que los estudiantes reflexionen dentro del tema a través de algunas preguntas: [...] ¿qué harías si volviera a pasar esto? ¿Crees que actuarías como tus padres o abuelos? (Narración, Lima, 2013.cit. en VALLE, 2017: 392)

Por lo tanto, el uso de las fuentes se complejiza. No se limita a la motivación o la lectura adicional, sino que se emplea para buscar evidencias del pasado y se contrastan visiones, lo cual corresponde a lo planteado como habilidades del pensamiento histórico.

El uso de diversas fuentes es considerado un desafío porque no siempre se sienten preparados. Hugo explica: 
Trato de darle énfasis [...] al tema de la constatación de fuentes. Me cuesta porque tampoco tengo todas las fuentes del mundo y no las conozco todas como para poder saber en todos los temas cuáles se contraponen, cuáles tienen visiones diferentes con respecto a un acontecimiento, a un proceso. Pero intento hacer eso. (Entrevista, Lima, 2013.cit. en VALLE, 2017: 395)

El acceso a una gama de fuentes diversas es un problema común para este grupo y para muchos docentes que desean emplearlas en el aula. La formación inicial no suele contribuir al manejo de fuentes primarias y de la historiografía, pues pareciera que se considera que esta es una labor más propia del historiador que del profesor de historia. Así, los estudiantes del profesorado reconocen esta situación como una debilidad.

No podemos afirmar que los integrantes de esta categoría compartan una sola representación de la historia reciente. Más bien como se observan diversas interpretaciones en las que se reconocen problemas arraigados en el país, como: la injusticia; el racismo; la corrupción; o la desigualdad. Pero estos problemas no permanecen invariables en el tiempo, se contextualizan y analizan dando lugar a una variedad de interpretaciones, lo cual nos permite identificar rasgos del paradigma posmoderno planteado por Benejam (2004).

Los estudiantes del profesorado de esta categoría evidencian una representación del aprendizaje de la historia en la que el alumnado: se aproxima al pasado a través de fuentes; establece vínculos entre el presente, el pasado y el futuro; relaciona y analiza causas y consecuencias. Además, consideran diversas perspectivas de los hechos. No buscan promover la transmisión de una interpretación "verdadera”, sino que manejan la opción de diversos puntos de vista sobre el proceso histórico. Aunque los propios estudiantes del profesorado reconocen ciertas limitaciones en su formación, consideran que aprender historia significa poder construir una interpretación histórica apoyada en fuentes, siendo conscientes de las diferencias entre el pasado y el presente, y pudiendo intervenir en la construcción del futuro. 


\section{Conclusiones}

La investigación evidencia que las representaciones de la enseñanza y del aprendizaje de la historia reciente recogen 3 ideas centrales. Por un lado, la necesidad de remitirse solamente a los acontecimientos -narradores-, ubicándose en un paradigma positivista. En segundo lugar, la de realizar una interpretación del proceso histórico reciente - “identitarios” y "reveladores"- que es considerada como la única válida. Ésta recoge elementos del paradigma crítico al analizar el pasado, pero niega a los estudiantes la posibilidad de cuestionar o plantear una interpretación propia. Finalmente, el entenderla a partir del análisis de problemáticas del presente cuyas raíces se identifican en el proceso histórico, siendo este grupo el más cercano al paradigma posmoderno.

Una representación importante es entender al maestro de historia como alguien que debe ser "objetivo"; los "narradores" porque se remiten a hechos y los "identitarios" y los "reveladores" porque poseen la "verdad objetiva" sobre el pasado. Solo los "analíticos" parecen entender que la historia implica interpretaciones de los procesos históricos, pero ello no los exime de sentir inseguridad frente a la historia reciente y buscar una postura neutral. Así, los estudiantes del profesorado temen expresar su posición frente al pasado reciente.

La investigación también ha permitido comprobar la influencia de sus experiencias previas como alumnos en su representación de cómo debe ser un maestro de ciencias sociales.

Sobre la representación de los contenidos, concluimos que lo identificado por Portocarrero y Oliart (1989) continúa vigente en los identitarios y los reveladores, aunque se le ha incorporado la corrupción como una característica adicional del pasado. En ambos domina una perspectiva negativa del pasado, que es entendida como una interpretación crítica porque cuestiona a los gobernantes. Debe resaltarse que la historia "crítica" se explica a partir del cuestionamiento al orden establecido, a los gobernantes y a las élites, pero no implica necesariamente un análisis que considera las habilidades del pensamiento histórico. 
Se concluye también que los futuros maestros consideran que carecen de la preparación para afrontar la historia reciente, tanto a nivel disciplinar como acerca de estrategias para abordarlos.

De acuerdo con el CNEB-2016, debería promoverse una representación del aprendizaje en la que el estudiante construye el conocimiento y desarrolla su pensamiento histórico. Así, el alumnado aprende a construir diversas interpretaciones. Sin embargo, concluimos que solo en el grupo de los "analíticos" las representaciones de la enseñanza y del aprendizaje favorecen el logro de la competencia. En los otros 3 grupos, las representaciones expresan una serie de barreras para el desarrollo del pensamiento histórico y el logro de la competencia. El principal problema es que se mantiene la representación de un aprendizaje transmisivo centrado en el maestro.

Finalmente, consideramos que es fundamental repensar los programas de formación inicial del profesorado, para que promuevan la reflexión continua sobre las representaciones que tienen y van construyendo sus estudiantes. Debería ponerse más atención a las necesidades de los futuros maestros para abordar la historia reciente, incorporando oportunidades para crear y discutir qué estrategias podrían emplearse. Asimismo, debería fortalecerse la formación disciplinar sobre estos temas y el desarrollo de las habilidades propias del pensamiento histórico de los futuros docentes, pues de ello depende su capacidad de enseñar a construir interpretaciones históricas.

\section{Referencias}

ADLER, Susan. The education of social studies teachers. In: LEVSTIK, Linda; TYSON, Cynthia. Handbook of research in social studies education. Nueva York: Routledge, 2008. p. 329-351.

ARMENTO, Beverly. Changing conceptions of research on the teaching of social studies. In: SHAVER, James. Handbook of research on social studies teaching and learning: a project of the National Council for the social studies. Nueva York: Macmillan, 1991. p. 185-196. 
AUDIGIER, Francois. Investigaciones en didáctica de la historia, de la geográfia, de la educación cívica y la formación de los docentes. In: ARRONDO, Cristina (comp.). La formación docente en el profesorado de historia. Rosario: Homo Sapiens, 2001. p.113-137.

AVERY, Patricia. Investigación sobre la enseñanza de las ciencias sociales y la educación del profesorado. In: AVILA, Rosa María; RIVERO, Pilar; DOMINGUEZ, Pedro (coord.). Metodología de investigación en diáctica de las ciencias sociales. Zaragoza: Institución Fernando el Católico, 2010. p. 337-368.

AMÉZOLA, Gonzalo de. Esquizohistoria: la historia que se enseña en la escuela, la que preocupa a los historiadores y una renovación posible de la historia escolar. Buenos Aires: Zorzal, 2008.

BENEJAM, Pilar. Las finalidades de la educación social. In: BENEJAM, Pilar; PAGĖS, Joan (coord). Enseñar y aprender ciencias sociales, geografía e historia en la educación secundaria. 4. ed. Barcelona: Horsori, 2004. p. 33-51.

CRESWELL, John. Research design: qualitative, quantitative and mixed approaches. 3. ed. Thousand Oaks: Sages, 2009.

CORBIN, Juliet; STRAUSS, Anselm. Basics of qualitative research: techniques and procedures for developing grounded theory. 3. ed. Thousand Oaks: Sage, 2008.

COMISIÓN DE LA VERDAD Y RECONCILIACIÓN [CVR]. Hatun Willakuy. Lima: CVR, 2004.

EPSTEIN Terrie; PECK, Carla. Teaching and learning difficult histories in international contexts: a critical sociocultural approach. Nueva York: Routledge, 2018.

FRANCO, Marina; LEVIN, Florencia. La historia reciente en la escuela: nuevas preguntas y algunas respuestas. Novedades Educativas, Buenos Aires, n. 202, p. 1-5, 2007.

GONZÁLEZ, María Paula. La Historia argentina reciente en la escuela: saberes y prácticas docentes en torno a la última dictadura. Los Polvorines: Universidad Nacional Genaral Sarmiento, 2014.

GONZÁLEZ, Gustavo. La formación inicial del profesorado y la educación para la ciudadanía: representaciones sociales, diseño de clases y prácticas de enseñanza. Enseñanza de las Ciencias Sociales, [Barcelona], n.12, p. 37-45, 2013. Disponible en: https://raco.cat/index.php/EnsenanzaCS/article/view/271367.

Acceso en: 15 diciembre 2019. 
JARA, Miguel. Representaciones y enseñanza de la historia reiente-presente: estudio de casos de estudiantes en formación inicial y en su primer año de docencia. Enseñanza de las Ciencias Sociales, [Barcelona], n. 11, p. 15-29, 2012. Disponible en: https://raco.cat/index.php/EnsenanzaCS/article/view/263452. Acceso en: 16 de diciembre 2019.

LÉVESQUE, Stephen. Thinking historically: educating students for the twentyfirst century. Toronto: University of Toronto Press, 2008.

LÉVESQUE, Stephen; CROTEAU, Jean-Philippe. Beyond history for historical consciousness: students' narrative, and memory. Toronto: University of Toronto Press, 2020.

MINISTERIO DE EDUCACIÓN DEL PERÚ. Programa curricular de eduación secundaria. Lima: Minedu, 2017.

MINISTERIO DE EDUCACIÓN DEL PERÚ. Currículo de la educación básica nacional 2016. Lima: Minedu, 2016.

MORA, Martín. La teoría de las representaciones sociales de Serge Moscovici. Athenea Digital, Barcelona, n. 2, p. 1-25, 2002. Disponible en: http://blues.uab.es/athenea/num2/Mora.pdf.Acceso en: 28 enero 2021.

MOSCOVICI, Serge. El psicoanálisis, su imagen y su público. 2. ed. Buenos Aires: Huemul, 1979.

ORTEGA, Delfin; PAGĖS, Joan. Las representaciones sociales de los problemas contemporáneos en estudiantes de magisterio de Educación Primaria.

Investigación en la escuela, Sevilla, n. 93, p. 1-15, 2017.

PAGĖS, Joan; SANT, Edda. Las representaciones del futuro profesorado de historia y ciencias sociales sobre los saberes sociales, geográficos e históricos. In: LA HISTORIA ENSEÑADA A DISCUSIÓN: retos epistemológicos y perspectivas didácticas. Morelia: Universidad Mochoacana de San Nicolás de Hidalgo, 2015. p. 2057-2072.

PAGĖS, Joan. El desarrollo del pensamiento histórico como requisito para la formación democrática de la ciudadanía. Reseñas de enseñanza de la historia, Cordoba, n. 7, p. 69-91, oct. 2009.

PAGÈS, Joan. Enseñar a enseñar historia: la formación didáctica de los futuros profesores de historia. NICOLÁS, Encarna; GÓMEZ, José Antonio (coord.).

Miradas a la historia. reflexiones historiográficas en recuerdo de Miguel Rodríguez Llopis. Murcia: Universidad de Murcia, 2004. p. 155-178. 
PAGĖS, Joan. El currículo de didáctica de las ciencias sociales en la formación inicial del profesorado: investigaciones sobre la enseñanza y el aprendizaje de la DCS. Modelos, contenidos y experiencias en la formación del profesorado de ciencias sociales. Huelva: Universidad de Huelva: Universidad Internacional de Andalucía, 2000. p. 41-58.

PORTOCARRERO, Gonzalo; OLIART, Patricia. El Perú desde la escuela. Lima: Instituto de Apoyo Agrario, 1989.

POZO, Juan; SCHEUER, Nora; MATEOS, María; PÉREZ ECHEVERRÍA, Pilar. Las teorías implícitas sobre el aprendizaje y la enseñanza. In: POZO, Juan et al. (eds.). Nuevas formas de pensar la enseñanza y el aprendizaje: las concepciones de profesores y alumnos. Barcelona: Graó, 2006. p. 95-134.

SANTISTEBAN, Antoni; GONZÁLES, Neus; PAGĖS, Joan. Una investigación sobre la formación del pensamiento histórico. SIMPOSIO INTERNACIONAL DE DIDÁCTICA DE LAS CIENCIAS SOCIALES, 21., 2010, Zaragoza. Actas [...]. Zaragoza: AUPDCS-UNIZAR, 2010. p.115-128. Tema: Metodología de investigación en didáctica de las ciencias sociales.

SEIXAS Peter; MORTON, Tom. The big six historical thinking concepts. Toronto: Nelson, 2013.

STABILI, María. Entre historias y memorias. Madrid: Iberoamericana AHILA, 2007.

TRINIDAD, Rocío. El espacio escolar y las memorias de la guerra en Ayacucho. In: JELIN, Elizabeth. Educación y memoria: la escuela elabora el pasado. Buenos Aires: Siglo Veintiuno, 2004. p. 11-39.

UCCELLI, Francesca; AGÜERO, José; PEASE, María; PORTUGAL, Tamia. Atravesar el silencio. Lima: IEP, 2017.

VALENCIA, Lucía; VILLALÓN, Gabriel; PAGĖS, Joan. Las representaciones sociales de la enseñanza de la historia del alumnado de dos universidades chilenas (USACH y UMCE): dos estudios de caso. Reseñas de la enseñanza de la Historia, Cordoba, n. 10, p. 59-88, 2012.

VALLE, Augusta. Para que no se repita: la enseñanza de la violencia interna en el Perú desde los docentes. In: IBAGÓN, Javier Silva Vega et al. (eds.). Afrontar los pasados controversiales y traumáticos: aproximaciones desde la enseñanza y el aprendizaje de la historia. Cali: Universidad del Valle y Universidad ICESI, 2021. p. 107-146. 
VALLE, Augusta. Los desafíos de la enseñanza de la historia en el Perú. Andamio Revista de Didáctica de la Historia, Valparaíso: Instituto de Historia, Facultad de Filosofía e Historia Pontificia Universidad Católica de Valparaíso, v. 1, n. 5, p. 1336, jul. 2018.

VALLE, Augusta. Los últimos 100 años de la Historia Peruana según los y las estudiantes del profesorado: estudio sobre sus representaciones de la historia y su conciencia histórica. 2017. Tesis (Doctorado en didáctica de la historia, la geografía y las ciencias sociales), Departamento de Didáctica de la Lenguna, la Literatura y las Ciencias Sociales, Universidad Autónoma de Barcelona, Bellaterra, 2017.495p. 